\title{
Epithelial apoptosis is a prominent feature of the epithelial barrier disturbance in intestinal inflammation: effect of pro-inflammatory interleukin-13 on epithelial cell function
}

\author{
F Heller ${ }^{1}$, A Fromm $^{2}$, AH Gitter ${ }^{2,3}$, J Mankertz $^{1}$ and J-D Schulzke ${ }^{1}$
}

In ulcerative colitis, the T helper type 2 proinflammatory cytokine Interleukin-13 (IL-13) contributes as effector cytokine to the epithelial changes associated with disturbed epithelial barrier function. This study aimed to investigate the underlying mechanisms in a colonic epithelial cell culture model. For studying these epithelial features in response to proinflammatory cytokines epithelial apoptosis was investigated by TdT-mediated X-dUTP nick end labeling (TUNEL) staining in HT-29/B6 cell monolayers. In contrast to interferon- $\gamma$, IL-13 significantly upregulated the apoptotic rate of cells, which was intensified by simultaneous exposure to tumor necrosis factor- $\alpha$. That this has a direct functional influence on epithelial barrier was shown by the caspase inhibitor $\mathrm{N}$-benzyloxycarbonyl-Val-Ala-Asp, which inhibited IL-13 induced apoptosis induction and concomitantly reversed the decrease in epithelial resistance by approximately $50 \%$. Direct evidence for apoptotic rosettes at corresponding sites of barrier defects in the epithelium was obtained by conductance scanning. In addition, the pore-forming tight junction protein claudin- 2 was found to be upregulated at protein and mRNA level. In conclusion, IL-13 disturbs intestinal barrier function through mechanisms including apoptosis induction and alteration of tight junction protein composition.

\section{INTRODUCTION}

Inflammatory processes as an e.g., inflammatory bowel disease are accompanied by altered barrier function of the intestine. ${ }^{1}$ This is relevant for two reasons. First, solutes and water from the circulation can reach the intestinal lumen to a larger extent and cause leak flux diarrhea. The second consequence regards the uptake of antigens, which can normally translocate across the epithelial barrier only in small amounts and may allow for immune tolerance induction. However, if the intestinal barrier is disturbed, elevated uptake of antigens may intensify or even initiate inflammation. Besides tight junction changes, also other structural changes in the epithelium as epithelial cell apoptosis induction, ${ }^{2-4}$ epithelial lesion induction and transcytosis acceleration can have a function. ${ }^{5,6}$

Mucosal immune regulation of the Thelper type 2 is observed in ulcerative colitis (UC). Here, interleukin (IL)-13 has been shown to be the key effector cytokine. ${ }^{7,8}$ Indeed, IL-13 causes barrier effects in cell models which are similar to those found in UC. Especially, induction of epithelial apoptosis is a prominent feature of the IL-13 effect, which we studied in detail with special attention to the functional role of apoptosis on the intestinal epithelial barrier.

\section{RESULTS}

Interleukin-13 influences epithelial barrier function of human colonic HT-29/B6 epithelial cells

To study the effect of IL-13 on epithelial barrier function, we measured the transepithelial electrical resistance $\left(R^{\mathrm{t}}\right)$ of HT29/B6 monolayers after addition of IL-13. IL-13 $\left(10 \mathrm{ng} \mathrm{ml}^{-1}\right)$ caused a decrease in $R^{\mathrm{t}}$ after $24 \mathrm{~h}$ to $76 \pm 2 \%$ of the initial resistance (Table 1). This effect of IL-13 was only obtained, when IL-13 was added basolaterally, while apical addition did not affect $R^{\mathrm{t}}$ (data not shown).

Approximately as much as $5 \mathrm{ng} \mathrm{ml}^{-1}$ tumor necrosis factor (TNF) $\alpha$ induced a drop in $R^{\mathrm{t}}$ to $68 \pm 9 \%$ after $24 \mathrm{~h}$ (Table 1 ).

${ }^{1}$ Department of Gastroenterology, Infectious Diseases and Rheumatology, Charité, Campus Benjamin Franklin, Berlin, Germany. ${ }^{2}$ Institute of Clinical Physiology, Charité, Campus Benjamin Franklin, Berlin, Germany. ${ }^{3}$ Present address: University of Applied Sciences, Jena, Germany. Correspondence: J-D Schulzke (joerg.schulzke@charite.de) 
Table 1 Epithelial barrier function of HT-29/B6 cells in response to proinflammatory cytokines

\begin{tabular}{llcc}
\hline Cytokine & Concentration & Duration (h) & $\begin{array}{c}\text { Resistance in \% } \\
\text { of initial value }\end{array}$ \\
\hline Control & No addition & 24 & $98 \pm 5$ \\
IFN $\gamma$ & $10 \mathrm{Uml}^{-1}$ & 24 & $86 \pm 5^{\mathrm{NS}}$ \\
IFN $\gamma$ & $1,000 \mathrm{Uml}^{-1}$ & 24 & $79 \pm 5^{\star \star}$ \\
TNF $\alpha$ & $5 \mathrm{ng} \mathrm{ml}^{-1}$ & 24 & $69 \pm 9^{\star \star}$ \\
IL-13 & $10 \mathrm{ng} \mathrm{ml}^{-1}$ & 24 & $76 \pm 2^{\star \star \star}$ \\
IL-13+TNF $\alpha$ & $10+5 \mathrm{ng} \mathrm{ml}^{-1}$ & 24 & $47 \pm 1^{\star \star \star}$ \\
\hline
\end{tabular}

IFN, interferon; IL, interleukin; TNF, tumor necrosis factor.

In HT-29/B6 cell monolayers, the influence of proinflammatory cytokines on electrical resistance was determined. NS, not significantly different from control; ${ }^{* \star} P<0.01 ;{ }^{* \star} P<0.001$

Given simultaneously, the effect of TNF $\alpha$ and IL-13 was additive ( $47 \pm 1 \%$ of initial resistance after $24 \mathrm{~h}$; Table 1$)$.

\section{IL-13 induces epithelial cell apoptosis}

To investigate the effect of IL-13 on epithelial apoptosis in HT29/B6 monolayers, apoptotic ratio was measured in control, TNF $\alpha$, and IL-13 treated cells. TUNEL-staining of adherent cells revealed typical changes associated with epithelial apoptosis such as condensation of chromatin and segmentation of the nucleus in TUNELpositive cells. The number of apoptotic cells was determined by manual counting in monolayers and by fluorescence activated cell sorting (FACS) scanning of single cell suspensions as indicated in Table 2. Control monolayers exhibited a rate of $1.0 \pm 0.5 \%$ apoptotic cells, whereas in IL-13 treated cultures the rate of apoptotic cells was increased to $5.6 \pm 0.9 \%$. Interferon- $\gamma$ did not affect apoptotic rate. By FACS scanning the number of apoptotic cells were determined in untreated cultures (1.6 $\pm 0.3 \%)$ and after incubation with $10 \mathrm{ngml}^{-1}$ of IL-13 (11.2 $\left.\pm 0.7 \%\right)$. Monolayers treated with the combination of IL-13 and TNF $\alpha$ showed $17.2 \pm 0.7 \%$ of apoptotic cells (data not shown). Increased apoptosis induced by IL-13 could be completely blocked by the addition of N-benzyloxycarbonyl-Val-Ala-Asp-fluoromethylketone (Z-VAD-FMK) (Table 2).

\section{Apoptotic conductance with and without IL-13 induction}

Apoptosis of single cells occurs spontaneously. Around such lesions, the surrounding epithelial cells form apoptotic rosettes. Using conductance scanning the local conductance of individual rosettes was studied in HT-29/B6 cells. Spontaneous apoptotic rosette conductance was $106 \pm 25 \mathrm{nS}(n=16)$ with a maximum conductivity of $360 \mathrm{nS}$. This was superposed to the overall conductivity measured in non-apoptotic areas of the monolayers (data not shown). After IL-13 incubation the median conductance of the rosettes was increased approximately eightfold to $826 \pm 185 \mathrm{nS}(P<0.01)$. The maximal conductance was $2830 \mathrm{nS}$ with only $25 \%$ of the analyzed apoptotic rosettes exhibiting a conductance below $400 \mathrm{nS}$ (data not shown).

\section{Contribution of epithelial apoptosis to the IL-13 effect on $R^{t}$}

To determine whether the IL-13 effect on epithelial barrier is exclusively because of induction of epithelial cell apoptosis, the
Table 2 Apoptotic rate of epithelial HT-29/B6 cells in response to proinflammatory cytokines

\begin{tabular}{llcl}
\hline Cytokine & Concentration & $\begin{array}{c}\text { Duration } \\
(\mathbf{h})\end{array}$ & Apoptotic rate in \% \\
\hline Control & No addition & 48 & $1.0 \pm 0.5$ (histology) \\
IFN $\gamma$ & $100 \mathrm{Uml}^{-1}$ & 48 & $1.1 \pm 0.5^{\mathrm{NS}}$ (histology) \\
$\mathrm{IFN} \gamma$ & $1,000 \mathrm{Uml}^{-1}$ & 48 & $1.2 \pm 0.4^{\mathrm{NS}}$ (histology) \\
$\mathrm{IL}-13$ & $10 \mathrm{ng} \mathrm{ml}^{-1}$ & 48 & $5.6 \pm 0.9^{\star * *}$ (histology) \\
Control & $\mathrm{No} \mathrm{addition}_{\text {IL-13 }}$ & 48 & $1.6 \pm 0.3$ (FACS) \\
IL-13+Z-VAD & $10 \mathrm{ng} \mathrm{ml}^{-1}$ & 48 & $11.2 \pm 0.7^{* * *}$ (FACS) \\
\end{tabular}

FACS, fluorescence activated cell sorting; IFN, interferon; IL, interleukin; Z-VAD, N-benzyloxycarbonyl-Val-Ala-Asp.

In HT-29/B6 cell monolayers, the influence of proinflammatory cytokines on apoptotic rate was determined. NS, not significantly different from control; ${ }^{* * *} P<0.001$ vs. control; ${ }^{\$} P<00.1$ vs. IL-13 addition without Z-VAD.

caspase inhibitor Z-VAD was applied. We found that caspase inhibition only partially blocked the decrease in resistance induced by IL-13. $R^{\mathrm{t}}$ dropped to $61 \pm 1 \%$ after addition of IL-13, whereas $R^{\mathrm{t}}$ of cultures treated with IL-13 and Z-VAD did only decrease to $81 \pm 1 \%(P<0.001)$. Z-VAD alone had no significant effect on $R^{\mathrm{t}}$ (data not shown) in accord with a rather low apoptosis rate in control cells. This indicates a second mechanism beside apoptosis to contribute to the effect of IL-13 on epithelial barrier function and therefore we checked for tight junction protein changes.

\section{IL-13 modifies the claudin composition of tight junctions}

To determine if changes in tight junction protein composition may cause the IL-13-induced decrease in $R^{\mathrm{t}}$ not accounted for by apoptosis, western blot analysis of cell membrane fractions were performed for the tight junction proteins claudin-1, claudin-2, and claudin- 4 and their expression was quantified by densitometry (Table 3). Although claudin- 1 and claudin- 4 remained unchanged by IL-13, IL-13 induced a threefold increase in expression of the pore-forming tight junction protein claudin-2 (295 $\pm 37 \%$ compared with controls).

This increased expression of claudin-2 is paralleled by an increased transcription of the claudin- 2 gene, as IL- 13 induced a significant increase of claudin- 2 mRNA as shown by real-time PCR. The amount of claudin-2 mRNA increases in HT29/B6 cells after $48 \mathrm{~h}$ of treatment with $10 \mathrm{ng} \mathrm{ml}^{-1}$ of IL-13 from $713 \pm 38$ to $1,208 \pm 40$ copies/ng total RNA $(n=5, P<0.001)$.

\section{DISCUSSION}

This study aimed to elucidate the cytokine-induced epithelial barrier disturbance observed in UC. Since IL-13 was recently identified to be the key effector cytokine in the Thelper type 2 response in UC, ${ }^{7}$ we concentrated on IL-13 effects on barrier function in our HT-29/B6 model. Special attention was given to the contribution of epithelial apoptosis to the barrier effect, as the functional role of epithelial apoptosis is still a matter of debate.

To quantify the effect of IL-13 on epithelial cell function, we measured the capacity of IL-13 to alter resistance of HT-29/B6 
Table 3 Effect of interleukin-13 on epithelial tight junction proteins

\begin{tabular}{ll}
\hline Tight junction-protein & $\begin{array}{l}\text { Expression in \% } \\
\text { of control values }\end{array}$ \\
\hline Claudin-1 & $99 \pm 2^{\mathrm{NS}}$ \\
Claudin-2 & $295 \pm 37^{\star \star}$ \\
Claudin-4 & $100 \pm 1^{\mathrm{NS}}$ \\
\hline
\end{tabular}

In HT-29/B6 cell monolayers, the influence of the proinflammatory cytokine interleukin-13 $(10 \mathrm{mg} / \mathrm{ml})$ was determined on tight junction protein levels in membrane fractions of HT-29/B6 cell monolayers. NS, not significantly different from control; ${ }^{* *} P<0.01$

monolayers. IL-13 had a profound effect. A drop in resistance developed already within $24 \mathrm{~h}$ and was long-lasting. Although IL-13 had already a significant effect when given alone, it was further enhanced by TNF $\alpha$. Interferon- $\gamma$, a marker cytokine of T helper type 1 responses, has also synergistic effects together with $\mathrm{TNF} \alpha,{ }^{9}$ but did only slightly affect $R^{\mathrm{t}}$ and not at all apoptotic rate in HT-29/B6. Several control experiments have been conducted to follow-up the mechanism of this IL-13 effect. Lactate dehydrogenase release assays did not yield evidence for a contribution of necrosis. ${ }^{8}$ Also, IL-13 treated cells were not different from control cells in light microscopy. Furthermore, immunofluorescence localization of occludin and zonula occludens protein-1 (ZO-1) did not indicate that IL-13 disrupts any part of the cell monolayer (data not shown).

It had been suggested before that apoptosis contributes to mucosal pathology in UC. ${ }^{2}$ To study the effect of IL-13 on epithelial apoptosis, we quantified the number of apoptotic cells in HT-29/B6 monolayers treated with IL-13. A pronounced increase by IL-13 was found. In support of a functional role of IL-13 induced epithelial apoptosis approximately half of the drop in transepithelial resistance was blocked by addition of the caspase inhibitor Z-VAD to HT-29/B6 monolayers before the treatment with IL-13. From these measurements it can be concluded that apoptosis induction contributes to approximately half of the drop of transepithelial resistance after IL-13 treatment of HT-29/B6 monolayers. Furthermore, evidence for a barrier contribution of apoptosis came from the analysis of the conductance associated with spontaneous and IL-13 induced apoptotic rosettes in HT-29/B6 cells which demonstrated deepening of local leaks at apoptotic sites with IL-13.

\section{Tight junctions are altered by proinflammatory cytokines}

IL-13 changed tight junction strand composition by increasing claudin-2 expression. That claudin-2 transfection to cell monolayers can increase cation permeability had already been shown before. ${ }^{10,11}$ In addition, the appearance of discontinuous tight junctions has been reported when L-fibroblast were transfected with claudin-2 c-DNA. ${ }^{12}$ Thus, this increase of claudin-2 expression observed here may indeed represent the second mechanism by which transepithelial resistance is decreased by IL- 13 beside the above mentioned induction of apoptosis.

\section{Barrier dysfunction in UC}

There are significant changes in epithelial tight junction structure and apoptotic rate in $\mathrm{UC},{ }^{1,8}$ which resembles those observed here for the effect of IL-13 on HT-29/B6 cells. Finally, an IL-13 dependent arrest in epithelial restitution ability (data not shown) may be responsible for apoptosis to develop into larger epithelial defects such as microerosions in UC. Taken together, the present data on IL-13 mechanisms and findings on UC-tissue strongly support the function of IL-13 as key effector cytokine in UC.

\section{METHODS}

HT-29/B6 cell culture. HT-29/B6 cells represent a subclone of the human colonic cell line HT-29, which grow as differentiated polarized monolayers. ${ }^{9}$ Cells were cultured in $25 \mathrm{~cm}^{2}$ culture flasks with culture medium containing RPMI-1640, 2\% L-glutamine, and 10\% fetal calf serum (all from Biochrom, Berlin, Germany). The $\mathrm{pH}$ was 7.4 in all experiments. Cultures were incubated at $37^{\circ} \mathrm{C}$ in a $95 \%$ air and $5 \%$ $\mathrm{CO}_{2}$ atmosphere. Cells were seeded on Millicell PCF filters (Millipore, effective membrane area $0.6 \mathrm{~cm}^{2}$; average concentration of $7 \times 10^{5}$ cells/ $\mathrm{cm})$. Three inserts were placed into one conventional culture dish (OD $60 \mathrm{~mm})$. Confluence was reached after 7 days. Experiments were performed on day 8 , giving $R^{\mathrm{t}}$ of approximately $500 \Omega \mathrm{cm}^{2}$. The apical compartment was routinely filled with $600 \mu$ land the basolateral compartment with $10 \mathrm{ml}$ culture medium. Cytokines (TNF $\alpha$, TEBU, Offenbach, Germany; IL-13, R\&D systems, Wiesbaden, Germany) were added basolaterally $48 \mathrm{~h}$ before the experiment to the cultures.

Monitoring of electrical resistance. $R^{t}$ of the monolayers was measured as described by Kreusel et al. ${ }^{13}$ Electrical measurements were performed in the culture dishes by two fixed pairs of electrodes (World Precision Instruments, Sarasota, FL). $R^{\mathrm{t}}$ was calculated from the voltage deflections caused by an external $\pm 10 \mu \mathrm{A}, 21 \mathrm{~Hz}$ rectangular current pulse. The temperature was maintained at $37^{\circ} \mathrm{C}$ during the measurements. Resistance values were corrected for the resistance of the filter and the bathing medium.

Conductance scanning technique. Conductance scanning was performed as described earlier. ${ }^{14}$ Monolayers were horizontally mounted in a modified Ussing chamber, which gave access to a scanning probe positioned close to the apical tissue side. The probe consisted of a pair of microelectrodes with tips set apart vertically by approximately $30 \mu \mathrm{m}$ $(\Delta z)$ that were connected to a differential amplifier and a bridge system with synchronous demodulation and was kept at a distance of $25 \mu \mathrm{m}$ to the epithelial surface. While a constant electric current (sinusoidal alternating current, $0.1 \mathrm{~mA} \mathrm{~cm}^{-2}, 24 \mathrm{~Hz}$ ) was passed through the monolayer the resulting electric field was detected. The current in the probe induced a voltage drop across the local resistance and thereby the apparent local conductivity $G_{\mathrm{A}}$ of the probe could be calculated from the scanning signal. The conductivity of the cell-culture filter support $\left(22 \mathrm{mS} \mathrm{cm}^{-2}\right)$ was subtracted and the conductance of apoptotic leaks was computed by spatial integration of $G_{\mathrm{A}}$.

Western blot analysis. Tight junction protein expression was determined by western blot analysis from membrane extracts as described earlier. ${ }^{15}$ HT-29/B6 cells were homogenized with iced lysate buffer for $10 \mathrm{~min}$ at $4^{\circ} \mathrm{C}$. After centrifugation $\left(30 \mathrm{~min}, 4^{\circ} \mathrm{C}, 43,000 \mathrm{~g}\right)$, the protein content of the supernatant was determined. Protein concentrations were determined by Pierce BCA assay. Aliquots of $5 \mu$ g were separated by polyacrylamide gel electrophoresis (12.5\%) and transferred to a polyvinylidene fluoride transfer membrane (NEN, Boston, MA). Blots were first blocked for $2 \mathrm{~h}$ in $5 \%$ milk powder in 5\% BSA followed by incubation with a primary antibody (Zymed, San Francisco, CA). Peroxidase-conjugated secondary antibodies and the chemiluminescence system Lumi-Light ${ }^{\text {PLUS }}$ (Roche, Mannheim, Germany) were used to detect bound antibodies.

Apoptosis assays. Apoptotic cells were stained with TUNEL assay (Roche, Mannheim, Germany). After cytokine treatment the cells were 
fixed with formaldehyde, stained for TUNEL and analyzed by microscopy Samples of IL-13 $\left(10 \mathrm{ng} \mathrm{ml}^{-1}\right)$ treated, interferon- $\gamma\left(10\right.$ to $\left.1,000 \mathrm{U} \mathrm{ml}^{-1}\right)$, $\mathrm{TNF} \alpha\left(5 \mathrm{ng} \mathrm{ml}^{-1}=500 \mathrm{U} \mathrm{ml}^{-1}\right)$, or untreated cells were compared. The apoptotic rate was calculated as percentage of TUNEL positive cells of total cell count. Alternatively, cells were brought into single cell suspensions with trypsin and resuspended at $2 \times 10^{7} \mathrm{cells} / \mathrm{ml}$ in PBS. After fixation with paraformaldehyde cells were permeabilized with $0.1 \%$ Triton $\mathrm{X}-100$ in $0.1 \%$ sodium citrate. Then apoptotic cells were stained with a TUNEL assay (Roche, Mannheim, Germany). Samples were analyzed by FACS with a FACS Calibur. Apoptosis was inhibited with the caspase inhibitor Z-VAD-FMK (Enzyme Systems Products, Livermore, CA).

Statistical analysis. All values are given as mean \pm s.e.m. The unpaired two-tailed $t$-test was used to determine the significance of differences. $P<0.05$ was considered significant.

\section{DISCLOSURE}

The authors have declared no financial interests.

() 2008 Society for Mucosal Immunology

\section{REFERENCES}

1. Schmitz, H. et al. A decrease in tight junction complexity contributes to the severely impaired epithelial barrier function in ulcerative colitis. Gastroenterology 116, 301-309 (1999).

2. Strater, J. et al. CD95 (APO-1/Fas)-mediated apoptosis in colon epithelial cells: a possible role in ulcerative colitis. Gastroenterology 113, 160-167 (1997).

3. Gitter, A.H., Bendfeldt, K., Schulzke, J.D. \& Fromm, M. Leaks in the epithelial barrier caused by spontaneous and TNF-alpha-induced single-cell apoptosis. FASEB J. 14, 1749-1753 (2000).
4. Gitter, A.H., Wullstein, F., Fromm, M. \& Schulzke, J.D. Epithelial barrier defects in ulcerative colitis: characterization and quantification by electrophysiological imaging. Gastroenterology 121, 1320-1328 (2001).

5. Soderholm, J.D. et al. Increased epithelial uptake of protein antigens in the ileum of Crohn's disease mediated by tumour necrosis factor alpha. Gut 53, 1817-1824 (2004).

6. Schurmann, G., Brüwer, M., Klotz, A., Schmidt, K.W., Senninger, N. \& Zimmer, K.P. Transepithelial transport processes at the intestinal mucosa in inflammatory bowel disease. Int. J. Colorect. Dis. 14, 41-46 1999).

7. Fuss, I.J. et al. Nonclassical CD1d-restricted NKT cells that produce IL-13 characterize an atypical Th2 response in ulcerative colitis. J. Clin. Invest. 113, 1490-1497 (2004).

8. Heller, F. et al. Interleukin-13 is the key effector Th2 cytokine in ulcerative colitis that affects epithelial tight junctions, apoptosis, and cell restitution. Gastroenterology 129, 550-564 (2005).

9. Schmitz, H. et al. Tumor necrosis factor-alpha (TNF $\alpha$ ) regulates the epithelial barrier in the human intestinal cell line HT-29/B6. J. Cell Sci. 112, 137-146 (1999).

10. Amasheh, S. et al. Claudin-2 expression induces cation-selective channels in tight junctions of epithelial cells. J. Cell Sci. 115, 4969-4976 (2002).

11. Furuse, M., Furuse, K., Sasaki, H. \& Tsukita, S. Conversion of zonulae occludentes from tight to leaky strand type by introducing claudin-2 into Madin-Darby canine kidney I cells. J. Cell Biol. 153, 263-272 (2001).

12. Furuse, M., Sasaki, H. \& Tsukita, S. Manner of interaction of heterogeneous claudin species within and between tight junction strands. J. Cell Biol. 147, 891-903 (1999).

13. Kreusel, K.M., Fromm, M., Schulzke, J.D. \& Hegel, U. Cl-secretion in epithelial monolayers of mucus-forming human colon cells (HT-29/B6). Am. J. Physiol. 261, C574-C582 (1991).

14. Gitter, A.H., Bertog, M., Schulzke, J. \& Fromm, M. Measurement of paracellular epithelial conductivity by conductance scanning. Pflugers Arch. 434, 830-840 (1997).

15. Burgel, N., Bojarski, C., Mankertz, J., Zeitz, M., Fromm, M. \& Schulzke, J.D. Mechanisms of diarrhea in collagenous colitis. Gastroenterology 123, 433-443 (2002). 